\title{
An umbilical nodule with cyclical changes
}

\author{
Matthias Möhrenschlager dermatologist ${ }^{1}$, Helmut P Arbogast surgeon ${ }^{2}$, Verena Henkel psychiatrist ${ }^{3}$ \\ ${ }^{1}$ Department of Dermatology and Allergology, Hochgebirgsklinik, Davos, Switzerland; ${ }^{2}$ Department of Surgery, Grosshadern Medical Centre, \\ Ludwig-Maximilians-Universität, Munich, Germany; ${ }^{3}$ Department of Psychiatry, Ludwig-Maximilians-Universität, Munich, Germany
}

\begin{abstract}
A 47 year old non-parous woman who had never had abdominal surgery was admitted with a four year history of an intermittently palpable nodule in the umbilical region. Initially, she noticed an increase in lesional size and pressure pain, which resolved within a few days. Six months before admission, blue-black discoloration appeared in the umbilical area; this vanished within a week but reappeared cyclically, along with an increase in size of the nodule and localised discomfort.

Macroscopic inspection during menstruation showed a sharply confined blue-black macule within the umbilical area. Lesional palpation identified a circumscribed, firm, well relocatable pea sized nodule just below the umbilical skin. Dermoscopy of the area showed features corresponding to a cutaneous haematoma.
\end{abstract}

\section{Questions}

1 What is the likely diagnosis?

2 Which differential diagnoses have to be considered?

3 Which diagnostic procedure(s) would be appropriate?

4 What kind of treatment would you recommend?

\section{Answers}

\section{What is the likely diagnosis? \\ Short answer}

Umbilical endometriosis.

\section{Long answer}

Figure 1 shows the umbilical area with a discrete central blue-black macule. The occurrence of this visible and palpable lesion with menses is characteristic of cutaneous umbilical endometriosis.

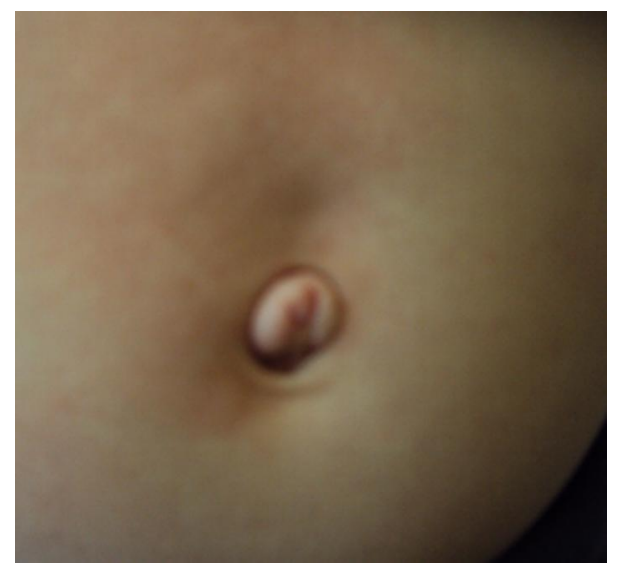

Fig 1 Abdominal region with umbilical haematoma during menses

Endometriosis is defined as the presence of endometrial tissue outside the uterine cavity. It occurs in $6-10 \%$ of women in the reproductive age group. ${ }^{1}$ Regions with endometrial tissue include pelvic organs - especially the ovaries, the uterosacral ligaments, pouch of Douglas, bowel, bladder, diaphragm, pleura, pericardium, brain, and skin..$^{2-7}$

The most pronounced symptoms of endometriosis are dysmenorrhoea, menorrhagia, pelvic pain, dyspareunia, infertility, and bowel irregularities. ${ }^{1}$ Depression occurs in $23.5-86 \%$ of patients with endometriosis and pelvic pain (13-38\% in those without pain). ${ }^{8-10}$

With regard to cutaneous lesions, endometriosis occurs most commonly in scars after surgical interventions. ${ }^{11}$ Umbilical endometriosis is rare, being seen in only $0.5-1.0 \%$ of patients with endometriosis. ${ }^{12-14}$ Patients may report cyclical localised swelling, pain, discharge, or bleeding from the umbilicus. The skin usually shows bluish-black discoloration. Umbilical endometriosis is seen in about $15 \%$ of patients with intraperitoneal endometriosis..$^{1516}$ 
Cutaneous endometriosis develops into a malignant tumour only rarely (0.3-1\% in surgical scars compared with $\sim 2.5 \%$ in ovarian endometriosis). ${ }^{17}{ }^{18}$

\section{Which differential diagnoses have to be considered?}

\section{Short answer}

Primary or metastatic malignant umbilical tumour, lipoma, lipoleiomyoma, abscess, cyst, hernia, granuloma, keloid, or a congenital malformation of the omphalomesenteric duct or urachus.

\section{Long answer}

Umbilical endometriosis must be differentiated from several disorders. Primary malignant umbilical tumours (such as melanoma, basal cell carcinoma, squamous cell carcinoma, myosarcoma) are rare, representing only about $20 \%$ of all malignant umbilical tumours, with the remainder being metastatic. ${ }^{19}$ Most often, filiae of an adenocarcinoma are found, but metastases from sarcoma, mesothelioma, melanoma, and others have also been detected. ${ }^{20}$

Non-malignant umbilical tumours include lipoma, lipoleiomyoma, abscess, cyst, hernia, granuloma, and keloid. ${ }^{21} 22$ Congenital malformations of the omphalomesenteric duct or urachus must also be considered. ${ }^{19}$

\section{Which diagnostic procedure(s) would be appropriate?}

\section{Short answer}

Inspection, palpation, ultrasound, computed tomography, magnetic resonance imaging, and biopsy with histopathological analysis.

\section{Long answer}

In addition to medical history, macroscopic inspection, and palpation, the following examinations are appropriate ${ }^{1623}$ :

- Magnetic resonance imaging

- Computed tomography

- Ultrasound scans

- Histopathological analysis of lesional tissue (fig 2).

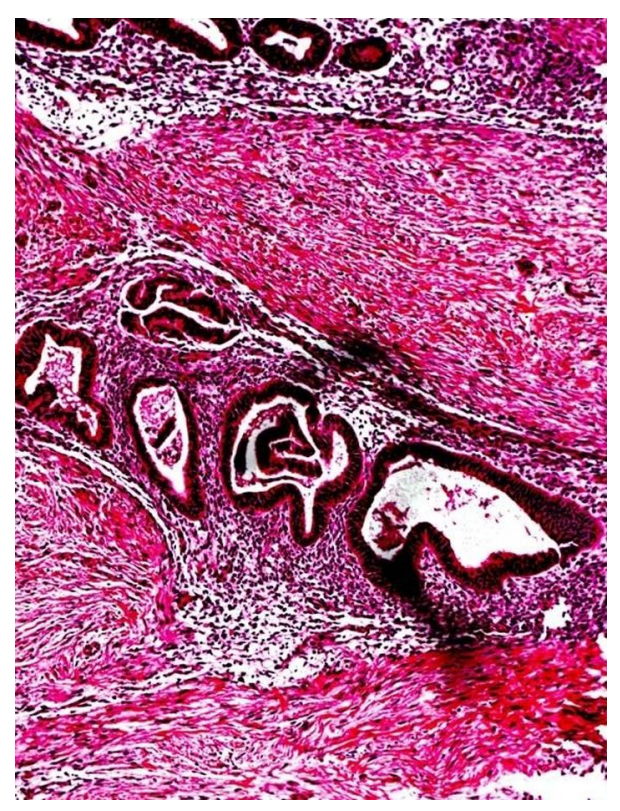

Fig 2 Histopathology of endometriosis (haematoxylin and eosin stain; magnification $\times 20$ ). Courtesy of Doris Mayr, Institute of Pathology, Ludwig-Maximilians University, Munich, Germany)

A single dermoscopy study on cutaneous endometriosis mentions the pathognomonic sign of "red atolls," which was not present in our patient. ${ }^{24}$

If pelvic manifestations of endometriosis are suspected, gynaecological examination, vaginal ultrasound, and laparoscopy may help to exclude the diagnosis or locate and remove tissue. ${ }^{16}$

The value of the serum CA125 concentration in the diagnosis of endometriosis has been debated. ${ }^{25}$

\section{What kind of treatment would you recommend?}

\section{Short answer}

Surgical excision and medical treatment.

\section{Long answer}

In umbilical endometriosis, a complete wide local excision is the treatment of choice. ${ }^{2}{ }^{114}$ In severe cases or in the presence of pelvic endometriosis, hormonal treatment aims to reduce the symptoms of endometriosis by suppression of luteinising hormone and follicle stimulating hormone. ${ }^{3}$ In this context, gonadotrophin releasing hormone agonists and other agents (including oral contraceptive pills, progestins, and synthetic androgens) have been used to induce atrophy of endometrial tissue. ${ }^{114162627}$

\section{Patient outcome}

Excision of the lesion with accompanying umbilical reconstruction proved successful. We did not start the patient on systemic treatment with gonadotrophin releasing hormone agonists or other agents for suppression of luteinising hormone and follicle stimulating hormone. Although local recurrence is uncommon, she was informed of the risk of endometriosis around the scar. Perioperative screening for depression was negative. ${ }^{28}{ }^{29}$ She is being followed up at the gynaecology department. 
Competing interests: All authors have completed the ICMJE uniform disclosure form at www.icmje.org/coi_disclosure.pdf (available on request from the corresponding author) and declare: no support from any organisation for the submitted work; no financial relationships with any organisations that might have an interest in the submitted work in the previous three years; no other relationships or activities that could appear to have influenced the submitted work.

Provenance and peer review: Not commissioned; externally peer reviewed.

Patient consent obtained.

1 Giudice LC. Endometriosis. N Engl J Med 2010;362:2389-98.

2 Dadwhal V, Gupta B, Dasgupta C, Shende U, Deka D. Primary umbilical endometriosis: a rare entity. Arch Gynecol Obstet 2010;283(suppl 1):119-20.

3 Bagade PV, Guirguis MM. Menstruating from umbilicus as a rare case of primary umbilical endometriosis: a case report. J Med Case Reports 2009;3:9326.

4 Victory R, Diamond MP, Johns DA. Vilar's nodule: a case report and systematic literature review of endometriosis external of the umbilicus. J Min Inv Gynecol 2007:14:23-32.

5 Spaziani E, Pichho M, Di Fillipo A, De Cristofano C, Ceci F, Stagnitti F. Spontaneous umbilical endometriosis: a case report with one year follow-up. Clin Exp Obstet Gynecol 2009;36:263-4.

6 Khaled A, Hammani H, Fazza B, Zermani R, Ben Jilani S, Kamoun MR. Primary umbilical endometriosis: a rare variant of extragenital endometriosis. Pathologica 2008;100:473-5.

7 Agarwal A, Fong YF. Cutaneous endometriosis. Singapore Med J 2008:49:704-9.

8 Chatzikokkinou P, Thorfinn J, Angelidis IK, Papa G, Trevisan G. Spontaneous endometriosis in an umbilical skin lesion. Acta Dermatovenerol Alp Panonica Adriat 2009;18:126-30.

9 Lorençatto C, Petta CA, Navarro MJ, Bahamondes L, Matos A. Depression in women with endometriosis with and without chronic pelvic pain. Acta Obstet Gynecol Scand 2006;85:88-92.

10 Waller KG, Shaw RW. Endometriosis, pelvic pain and psychological functioning. Fertil Steril 1995;63:796-800.

11 Nirula R, Greaney GC. Incisional endometriosis: an underappreciated diagnosis in general surgery. J Am Coll Surg 2000;190:404-7.

12 Michowitz M, Baratz M, Stavorovsky M. Endometriosis of the umbilicus. Dermatologica 1983;167:326-30.
13 Singh KK, Lessels AM, Adam DJ, Jordan C, Miles WF, Macintyre IM, et al. Presentation of endometriosis to general surgeons: a 10-year experience. Br J Surg 1995:82:1349-51.

14 Lee A, Tran HT, Walters RF, Rosenman K, Sanchez MR. Cutaneous umbilical endometriosis. Derm Online $J$ 2008; 14:23.

15 Sidani MS, Khalil AM, Tawil AN, El-Hajj MI, Seoud MA. Primary umbilical endometriosis. Clin Exp Obstet Gynecol 2002;29:40-1.

16 Mechsner S, Bartley J, Infanger M, Loddenkemper C, Herbel J, Ebert AD. Clinical management and immunohistochemical analysis of umbilical endometriosis. Arch Gynecol Obstet 2009;280:235-42.

17 Chene G, Darcha C, Dechelotte P, Mage G, Canis M. Malignant degeneration of perianal endometriosis in episotomy scar, case report and review of the literature. Int $J$ Gynecol Cancer 2007;17:709-14

18 Van Gorp T, Amant F, Neven P, Berteloot P, Leunen K, Vergote I. Endometriosis and the development of malignant tumours of the pelvis. Best Pract Res Clin Obstet Gynecol 2004;18:349-71.

19 Steck WD, Helwig EB. Tumors of the umbilicus. Cancer 1965;18:907-15.

20 Shetty MR. Metastatic tumors of the umbilicus: a review 1830-1989. J Surg Oncol 1990;45:212-5.

21 Lalor PF, Uribe A, Daum GS. De novo growth of a large preperitoneal lipoleiomyoma of the abdominal wall. Gynecol Oncol 2005;97:719-21.

22 Ilica AT, Mentes O, Gur S, Kocaoglu M, Bihci A, Coban H. Abscess formation as a complication of a ruptured urachal cyst. Emerg Radiol 2007;13:333-5.

23 Amato M, Levitt R. Abdominal wall endometriosis. CT findings. J Comput Assist Tomogr 1984;8:1213-4.

24 Di Giorgi V, Massi D, Mannone F, Stante M, Carli P. Cutaneous endometriosis: non-invasive analysis by epiluminescence microscopy. Clin Exp Dermatol 2003:28:315-7.

25 Socolov R, Butureanu S, Angioni S, Sindilar A, Boiculese L, Cozma L, et al. The value of serological markers in the diagnosis and prognosis of endometriosis: a prospective case-control study. Eur J Obstet Gynecol Reprod Biol 2011;154:215-7.

26 Jackson B, Telner DE. Managing the misplaced. Can Fam Physician 2006;52:1420-4.

27 Purvis RS, Tyring SK. Cutaneous and subcutaneous endometriosis: surgical and hormonal therapy. J Dermatol Surg Oncol 1994:20:693-5.

28 WHO. World Health Organization info package: mastering depression in primary care. 1998.

29 Henkel V, Mergl R, Kohnen R, Maier W, Möller H-J, Hegerl U. Identifying depression in primary care: a comparison of different methods in a prospective cohort study. BMJ 2003;326:200-1.

Cite this as: BMJ 2011;343:d5855

(C) BMJ Publishing Group Ltd 2011 